\title{
Rational-Emotive Behavior Therapy Program for Trauma-Specific Beliefs Among Undergraduate Students: Testing the Effect of A Group Therapy
}

\author{
Chiedu Eseadi ${ }^{1}$, Eke Kalu Oyeoku ${ }^{1}$, Liziana N. Onuigbo ${ }^{1}$, Mkpoikanke S. Otu $^{1}$, \\ Bartholomew Chinweuba Nwefuru ${ }^{1} \&$ Nkechinyere Charity Edeh ${ }^{2}$ \\ ${ }^{1}$ Department of Educational Foundations, University of Nigeria, Nsukka, Nigeria \\ ${ }^{2}$ Department of Social Science Education, University of Nigeria, Nsukka, Nigeria \\ Correspondence: Eke Kalu Oyeoku, Department of Educational Foundations, University of Nigeria Nsukka, \\ P.M.B. 410001, Enugu State, Nigeria. E-mail: eke.oyeoku@unn.edu.ng
}

Received: May 12, 2019 Accepted: June 15, 2019 Online Published: June 27, 2019

doi:10.5539/gjhs.v11n8p61 URL: https://doi.org/10.5539/gjhs.v11n8p61

\begin{abstract}
Background/Objective: The identification of trauma and posttraumatic stress disorder and its treatment is critically important in contemporary society. This preliminary research aimed to investigate the effect that rational-emotive behavior therapy (REBT) had on trauma-specific beliefs.
\end{abstract}

Method: This study used a randomized controlled trial design. The study participants were 182 undergraduate students. A self-report questionnaire which measures trauma-specific irrational beliefs was used for data collection. A trauma-focused REBT manual guided the group intervention. Within x Between-subjects and paired $t$-test statistic were used for data analysis.

Results: The results show that REBT brought about a significant reduction in trauma-specific irrational beliefs among the students in the treatment group compared to their counterparts in the waitlist control group. Finally, the results indicate that the positive gains were significantly maintained by the treatment group at four months follow-up.

Conclusion: The current study suggests that an REBT program can be helpful in altering trauma-specific irrational beliefs. The authors employed this model of psychological intervention in an African society in which trauma is significant. The authors demonstrated a model for evaluation and a model of intervention that appears to be of a significant and enduring impact as reported in this study.

Keywords: undergraduate students, group psychotherapy, rational-emotive behavior therapy, trauma, trauma-specific beliefs, Nigeria, posttraumatic stress disorder

\section{Introduction}

\subsection{Trauma and Posttraumatic Stress Disorder}

Several authors and researchers indicate that the recognition of trauma and posttraumatic stress disorder (PTSD) and its management is critically important in contemporary society (e.g. Bryant-Davis, Ellis, \& Edwards, 2013; Cacciatore, 2007; Courtois \& Ford, 2016; Giles et al., 2007; Harvey, 2007; Karatzias, Ferguson, Gullone, \& Cosgrove, 2016; Kuriansky \& Nemeth, 2013;Liotta, Springer, Misurell, Block-Lerner, \& Brandwein, 2015; Lynch, 2011; Mendelsohn, Herman, Schatzow, Kallivayalil, Levitan, \& Coco, 2011; Tummala-Narra, Kallivayalil, Singer, \& Andreini, 2012; Quiros \& Berger, 2015; Wöller, 2010). According to van der Kolk (1997), trauma is the consequence of exposure to an unavoidably stressful occasion that engulfs an individual's coping mechanisms. Quiros and Berger (2015) noted that trauma experiences are intrinsically complex and exposes victims to a wide array of responses that affect all facets of their lives. Trauma often leads the victims to question their beliefs whilst destroying their assumptions of trust (Counselling Directory, 2017). Trauma-exposed individuals exhibit feelings of shame, self-blame, and powerlessness, which contribute to difficulties in self-care and associating with others (Tummala-Narra, Kallivayalil, Singer, \& Andreini, 2012). According to Horowitz (2015), traumatic events can result in numerous responses such as disturbances of conscious sensations that span from intrusive thoughts and images to emotional numbing. The most frequently used term to depict the symptoms of psychological trauma is 
PTSD, which include distressing thoughts and maladaptive beliefs following exposure to an extremely traumatic event (Counselling Directory, 2017; Dawne, Shipherd, \& Resick, 2010; Tran, Moulton, Santesso, \& Rabb, 2016). PTSD can affect any person who has personally experienced a life-threatening event, witnessed the event, or learnt about it (American Psychiatric Association, 2013; Onana, 2016).

Several studies from Nigeria confirm the existence of PTSD among the student population (e.g. Busari, 2014; Nwoga, Audu, \& Obembe, 2016; Onyencho, Omeiza, \& Wakil, 2014; Tagurum et al., 2014). Among a Nigerian sample, Busari (2014) found that the lifetime occurrence of assaultive violence was $62.5 \%$ in males and $33.6 \%$ in females. Busari reported that females had a higher risk of PTSD than males. Nwoga et al. (2016) showed that the prevalence of PTSD among university students was $23.5 \%$. Using a sample of 351 undergraduate students, Onyencho et al. (2014) found a prevalence of $17.8 \%$ for PTSD. Furthermore, Tagurum et al. (2014) found that the personal experience of ethnoreligious violence, loss of property or means of livelihood, and death of a family member/friend were all significantly associated with the presence of PTSD in a Nigerian sample. The evidence from these previous studies suggests that PTSD is present in Nigerian student populations. However, less is known about the impact of any group psychotherapeutic interventions designed to assist trauma-exposed Nigerians, particularly, the students.

\subsection{Application of Group Therapy in the Treatment of Trauma}

Cooper, Hudson, Kranzberg, and Motherwell (2017) noted that trauma is best treated in groups since it occurs in both large (community, society) and small (family, couples) groups. Several authors are of the opinion that group therapy enables victims of trauma to connect with others who really understand what they have been through (e.g. Mendelsohn, Zachary, \& Harney, 2007; Pearlman \& Saakvitne, 1995). According to Ulman (2004), the capability of groups to offer support and reconnections for members is very essential for trauma treatment. Groups can also provide the victims a safe, nurturing and accepting atmosphere to talk about their traumatic experiences, feelings, and behaviors without fear of judgment from others who have not been through a similar experience (American Group Psychotherapy Association [AGPA], 2004). Thus, the benefits of group therapy include its effectiveness in provision of treatment and the potential of group members to offer social support to each other, which is crucial for clients who have PTSD (Brewin, Andrews, \& Valentine, 2000; Committee on the Assessment of Ongoing Effects in the Treatment of Posttraumatic Stress Disorder \& Institute of Medicine, 2012; Ozer, Best, Lipsey, \& Weiss, 2003). Furthermore, the rationale for using group therapy to assist victims of trauma is based on the need and benefit for them to join with others in therapeutic work when coping with victimization consequences such as social isolation, alienation, and diminished feelings (Foy, Unger \& Wattenberg, 2004).

In addition, groups provide an opportunity for therapists to help members understand their unrealistic and maladaptive thinking, defenses, and behavior as impacted by traumatic experience (Schermer, 2004). Groups offers unique opportunities for therapists to address the areas in which traumatized people have been the most affected (Klein \& Schermer, 2000). The special characteristics and curative factors that groups bring in general to psychotherapeutic treatment also apply to the treatment of trauma (Klein \& Schermer, 2000; Foy et al., 2000; Ulman, 2004). Groups can foster curative factors such as instillation of hope, universality, imparting of information, altruism, corrective recapitulation of primary family groups, development of socializing techniques, imitative behavior, interpersonal learning, group cohesiveness, catharsis, and existential factors among victims with traumatizing experiences (Behenck, Gomes, \& Heldt, 2016; Diefenbeck, Klemm, \& Hayes, 2014; Kageyama, Nakamura, Kobayashi, \& Yokoyama, 2016; Rice, 2015; Santos, Oliveira, Munari, Peixoto, \& Barbosa, 2012; Ulman, 2004; Yalom \& Leszcz, 2005). Groups can help members deal with social isolation and cultural barriers that often occur as a result of trauma, in that it provides multiple opportunities for shared experiences, mutual support and validation, learning from one another, and altruism that group members can provide to one another (Substance Abuse and Mental Health Administration, 2012; Yalom \& Leszcz, 2005). Thus, groups can be helpful in providing and enhancing therapy for clients suffering from PTSD.

\subsection{Efficacy of Group Therapy in the Treatment of Trauma}

Group therapy remains a popular treatment modality for trauma-exposed individuals (Heindel, 2011; Kar, 2011; Tran et al., 2016; Wöller, 2010).However, to our knowledge,only one Nigerian study has used group therapeutic intervention to successful mitigate the multiple effects of complex trauma including irrational thoughts and beliefs among adult participants (Eseadi, Anyanwu, Ogbuabor, \& Ikechukwu-Ilomuanya, 2015). The study participants were 26 adult Nigerians who provided retrospective reports about their traumatic childhood experiences. It was a 12-weeks manualized group intervention with a two-week follow-up (see Eseadi et al., 2015). Among the available group therapy methods, cognitive behavior therapy (CBT) approach is considered the first choice of treatment for PTSD sufferers due to its efficacy in alleviating PTSD symptoms arising from various types of trauma (see Beck \& 
Coffey, 2005; Cottraux et al., 2008; DuHamel et al., 2010; Hien et al., 2004; Kar, 2011; Mueser et al., 2008; Shemesh et al., 2011; Sijbrandij et al., 2007; Van Emmerik, Kamphuis, \& Emmelkamp, 2008; Wagner, 2003; Zoellner, Rabe, Karl \&, Maercker, 2011). Systematic reviews of effectiveness studies which compared several psychological treatments for traumatized individuals found that CBT was efficacious in the reduction of PTSD symptoms at posttreatment (Bisson\& Andrew, 2007; Kar, 2011; Mendes et al., 2008). At present, trauma-focused CBT is recommended for managing PTSD symptoms by various treatment guidelines and expert consensus panels due to its evidence-based efficacy (Bisson et al., 2010; Expert Consensus Panels for PTSD, 1999; Forbes et al., 2007; Garakani, Hirschowitz \& Katz, 2004; National Institute for Clinical Excellence, 2005). These research outcomes, existing guidelines, and expert recommendations informed our choice of the CBT approach to assist Nigerian clients suffering from PTSD.

CBT refer to a directive, time-constricted, structured treatment approach used for the treatment of a wide variety of mental health disorders. CBT is used to examine the links between client's thoughts, emotions and behaviors and to alleviate distress by helping the client to develop more adaptive cognitions and behaviors (Fenn \& Byrne, 2013). Thus, the principle underlying the utilization of CBT is that the client's affect and behaviors are chiefly determined by the way they imagine and structure the world around them (Kar \& Misra, 2008). The use of groups in CBT provides an opportunity for members to construct and tell their trauma narratives in the presence of witnesses, to give meaning to the trauma and to begin the process of mourning in the context of a supportive social environment (Ulman, 2004). Improvements in PTSD symptoms and changes in the behaviors of victims usually begin as soon as they begin to think and act more realistically and adaptively with respect to their situational and psychological difficulties (Kar, 2011). There are various types of CBT for PTSD, such as rational-emotive behavior therapy (REBT), which was the earliest type of CBT.

\subsection{Rational Emotive Behavior Therapy Group and Trauma}

REBT, created by Albert Ellis in 1955, can be applied in group therapy. According to REBT, responding to a traumatic life event with a set of irrational beliefs can play a key role in predicting the development of PTSD (Ellis, 2001). REBT's proposition is that individuals face undesirable activating events, about which they have rational and irrational beliefs. These beliefs can result in emotional, behavioral, and cognitive consequences. Whereas rational beliefs lead to functional consequences, the irrational beliefs lead to dysfunctional consequences (Turner, 2016; Wood, Turner, Barker, \& Higgins, 2017). Therefore, REBT clients are encouraged to vigorously dispute their irrational beliefs and to learn to develop rational beliefs, which can positively impact their emotional, cognitive, and behavioral responses (David, Lynn, \& Ellis, 2010; Ellis, 1994; 1962; Walen, DiGiuseppe, \& Dryden, 1992). REBT groups are usually didactic, philosophical, skills-oriented, directive, experiential, and supportive in nature (Northwest Frontier Addiction Technology Transfer Center [NFATTC], 2004). The REBT groups can allow members to share problems and enable them and the group leader to give feedback and suggestions (Eseadi, Ezurike, Ossai, \& Obidoa, 2017).

The REBT groups are leader-centered groups, and the leader encourages rational thinking among group members, encourages members to act as auxiliary counselors for other members, and serves as a model for group members (NFATTC, 2004). Apart from concentrating on the tendencies of people to construct and create their own emotional difficulties, REBT group therapy fully recognizes the interactions of human thoughts, feelings, and actions and active-directively makes use of a variety of cognitive, emotive, and behavioral group therapy techniques (Ellis, 1992) in helping individuals deal with traumatizing experiences. According to Corey (1991), REBT is suitable for group therapy in that it allows both members and group leaders to observe individual members' behavior and give feedback, provide opportunities for members to practice new behaviors involving risk-taking activities, do homework assignments, and experience role-playing activities.

\subsection{REBT and Trauma-Specific Beliefs}

REBT is based on the ABCDE framework, where A stands for activating events, $\mathrm{B}$ for beliefs, $\mathrm{C}$ for a range of psychological outcomes, D for disputation and $\mathrm{E}$ for efficient rational beliefs. REBT approach states that psychological outcomes are not created by A (the activating events), but by how an individual cognitively processes them (beliefs about A). REBT practitioners categorize beliefs into two major aspects, namely, rational beliefs (RBs) and irrational beliefs (IBs) (Addis \& Bernard, 2002; Bond \& Dryden, 2000; Choudhury, 2013; David, 2014; David, Lynn, \& Ellis, 2010; Ellis \& Dryden, 2007; Gavit, David, DiGiuseppe, \& DelVecchio, 2011; Koopmans, Sanderman, Timmerman, \& Emmelkamp, 1994; Martin, \& Dahlen, 2004; Turner, 2016). According to REBT experts, RBs refer to beliefs that have empirical, logical, and/or pragmatic backing. When RBs interacts with A, they create functional psychological consequences. On the other hand, IBs refer to beliefs that do not have empirical, logical, and/or pragmatic backing. When IBs interacts with A, they create dysfunctional psychological 
consequences (David, 2014; David, Lynn, \& Ellis, 2010). In other words, IBs are unrealistic thinking processes by which an individual interprets external events. Therefore, REBT clients are encouraged by the therapist to therapeutically dispute (D) their IBs, and to adopt more efficient (E) RBs (David, Lynn, \& Ellis, 2010; Onyechi, Eseadi, Okere, \&Otu, 2016).

In this study, trauma-specific irrational beliefs are seen as dysfunctional beliefs that are caused by the experience of one or more traumatic situations or events. Trauma-specific irrational beliefs can be regarded as posttraumatic cognitions. Posttraumatic cognitions are dysfunctional trauma-related beliefs which are capable of affecting posttrauma adaptation (Blayney, Read, \& Colder, 2016). Using an REBT approach, Hyland, Shevlin, Adamson, and Boduszek (2013) examined the role of trauma-specific irrational beliefs in the prediction of posttraumatic stress responses, while controlling for a range of important sociodemographic factors, in a sample of 313 trauma-exposed military and law enforcement personnel. The authors found that trauma-specific irrational beliefs significantly predicted belonging to the group reporting strong symptoms of PTSD rather than belonging to the group reporting mild symptoms of PTSD. In a recent study, Hyland, Shevlin, Adamson, and Boduszek (2015) also showed that an REBT-based model provided a satisfactory model fit and explained $89 \%$ of the variance in posttraumatic stress symptomatology, and general-level irrationality indirectly affected posttraumatic stress responses through a set of trauma-specific irrational beliefs. The binary logistic regression results also showed that trauma-specific beliefs significantly predicted belonging to the group reporting strong symptoms of PTSD compared to those reporting mild symptoms of PTSD. A total of 313 trauma-exposed military and law enforcement workers participated in the study and were categorized into two groups based on the intensity of reported PTSD symptomology.

Several studies indicate that exposure to traumatic events can result in significant distortions in an individual's beliefs about himself, others, and the world in major areas like safety, control, trust, intimacy, and esteem (e.g. Foa et al., 1999; Kaysen, Scher, Mastnak, \& Resick, 2005; McCann, Sakheim, \& Abrahamson, 1988; Messman-Moore \& Resick, 2002; Owens \& Chard, 2001; Owens, Pike, \& Chard, 2001; Wenninger \& Ehlers, 1998). According to Kira (2001), a person's belief system about life, death, and destiny adds to regulating the processing of traumas and managing the terrors activated by them. Thus, a traumatized individual may become a suicide bomber if he develops a specific belief system concerning death, life, and destiny that justifies this action. On the contrary, such an individual can cope in a different and helpful way with his trauma using different belief systems about life, death, and survival. In this regard, Orosa, Brune, Huter, Fischer-Ortman, and Haasen (2011) stated that belief systems serve as coping factors for traumatized individuals. According to Orosa et al. (2011), traumatized individuals who had strong belief systems demonstrated better improvement in therapeutic process, and their preceding level of traumatization did not impede the effectiveness of the therapeutic assistance given to them. According to Substance Abuse and Mental Health Services Administration (SAMHSA) (2014), the effects of trauma on an individual may depend on a number of factors such as characteristics of the individual, the type and characteristics of the event, the meaning of the trauma, and sociocultural factors.

\subsection{Cultural Considerations in Trauma-specific Beliefs}

Given that Nigeria is a multicultural society, many individuals frame their reactions to trauma based on collectivist cultural beliefs, practices, and local vocabularies of distress symptoms (see Erinosho 2015; Omololu, Ogunlade, \&Alonge, 2002). Many Nigerians might view trauma from a sociocultural lens that will likely lead to the creation of an adaptive or maladaptive cultural meanings of traumatic events. Some of the factors which may determine the way Nigerian people understands trauma include familial and cultural norms, mores, beliefs, values, and practices, religion, gender orientation, extent of acculturation, level of social support, social network, ethnicity, socioeconomic status, family types, and level of literacy among others (Anugwom \& Anugwom, 2016; Anum, Zawua, \& Sar, 2016; Dada-Adegbola, 2004; Jegede, 1981; Lasebikan, Owoaje, \& Asuzu, 2012). Oluwabamide, \& Umoh, 2011). Historically, in our cultures, many individuals also frame their reactions to trauma within the context of religion, with clergies, priests, diviners and herbalists interpreting the causes and meanings of traumatic events, while also serving as trauma-informed traditional healers (Ademuwagun, 1969; Dada, Yinusa, \& Giwa, 2011; Herbert \& Forman, 2010; Jegede, 1981; Oluwabamide \& Umoh, 2011; Osuji, 1993; Oyebola, 1980; Udosen, Otei, \& Onuba, 2006). Since culture-related beliefs could be possible antecedents of mental illness, the need for cultural sensitivity in healing trauma cannot be overemphasized (Cooper et al., 2017; Erinosho, 2015; Eseadi \& Ikechukwu-Ilomuanya, 2015). According to Cooper et al. (2017), treatment can be successful when therapists are open to non-traditional approaches and learn from the practices of other cultures.

From an REBT perspective, according to David and DiGiuseppe (2010), RBs and IBs derive from our social-cultural environment. That is, the environment infuses rational and/or irrational meanings into our 
understanding of us and the world. Therefore, the human mind comprises mainly of representations of social/cultural information (e.g., RBs and IBs) and representations. In this regard, a person exposed to an environment rich in IBs will probably endorse IBs, while a person exposed to an environment rich in RBs will mostly endorse RBs. Thus, people become rational and irrational largely due to their education and learning history and the social/cultural environment they live in (David \& DiGiuseppe, 2010). If so, it is possible that these beliefs might be quite different in the Nigerian sample as compared to other samples used in previous research of REBT and PTSD. However, Dryden, David, and Ellis (2010) argued that disturbance-creating IBs that are present in one's society could also be present in other social and cultural groups. Conversely, one can infer that RBs present in our society might also be present in other sociocultural groups.

Therefore, REBT therapists need to be familiar with the clients' culture, being able to know whether they identify with collectivist or individualistic perspectives. Also, recognizing clients" "social legacy" and their "social narrative" is important (Volkas, 2014). The social legacy is the instruction parents pass on to their offspring about how to get along in the world (Cooper et al., 2017). The social narrative is the story behind the teaching. For instance, a story of communal defeat or triumph (Cooper et al., 2017). This is feasible given that societies bond around a "chosen trauma" or "chosen glory" (Mojovic, 2011). According to Nicolas, Arntz, Hirsch, and Schmiedigen (2009), therapists have to be open to leaving their offices and modifying treatment in order to reconnect clients with their supportive community.

\subsection{Developmental Processes within the Context of Trauma}

The importance of highlighting ongoing developmental processes within the context of trauma cannot be overemphasized in this population. According to SAMHSA (2014), how traumatic event(s) affects a person is also dependent on developmental processes. As a result, each age group is susceptible in distinctive ways to the stresses of a traumatic event. Early adults may display depression and social withdrawal, increased risky activities such as sexual acting out, rebelliousness, yearning for revenge and action-oriented reactions to trauma, sleep and eating disturbances (Hamblen, 2001). In this regard, SAMHSA (2014) also noted that common upheavals observable in trauma-exposed individuals who are in their early adulthood stage include sleep problems, increased agitation, hypervigilance, isolation or withdrawal, and increased use of alcohol or drugs. According to the American Psychological Association Presidential Task Force on Posttraumatic Stress Disorder in Children and Adolescents (2008), many of the debilitating responses displayed by such individuals who have been exposed to traumatic events may include development of new fears, sleep disturbance, nightmares, sadness, loss of interest in normal activities, reduced concentration, decline in schoolwork, anger, somatic complaints and irritability. The individual's ability to effectively function in the family, peer group, or school may be impaired due to these symptoms.

\subsection{Study Objective and Hypotheses}

To our knowledge, interventional studies on the effect of an REBT program on trauma-specific beliefs of traumatized individuals in the Nigerian setting is limited, despite increasing research evidence on the consequences of exposure to traumatic situations and events. Therefore, the main objective of the current study was to examine the effect of an REBT program on trauma-specific irrational beliefs in a sample of undergraduate students in tertiary institutions in Southeast Nigeria. This was considered necessary given that the unhelpful consequences of trauma go beyond the healthcare system to educational sectors (Sypniewski, 2016). It was hypothesized that an REBT program would lead to a reduction in trauma-specific irrational beliefs in this student sample. Finally, the study hypothesis aimed to verify whether the treatment group would sustain the effects at follow-up.

\section{Method}

\subsection{Ethical Approval}

The approval for carrying out the present study was granted by the Research Ethics Committee, Faculty of Education at the University of Nigeria, Nsukka. The participants' written informed consent was obtained after explaining the aim of the research to them. The authors adhered to the guidelines for research with human participants by the American Psychological Association (2010).

\subsection{Participants}

This study was conducted using a sample of 182 traumatized undergraduate students in public tertiary institutions (i.e., higher education institutions which include universities, polytechnics, monotechnics, and colleges of education) in Southeast Nigeria who met the study inclusion criteria. The inclusionary criteria for the study were as follows: being a student in a tertiary institution situated in southeast Nigeria, being able to understand and speak 
Igbo language, having an extreme level of trauma-specific irrational beliefs based on categorization of traumatization in previous studies (Brune et al., 2002; Orosa et al., 2011), having experienced, witnessed or heard of one or more of the following traumatic events, such as the sudden death of a family member/friend, a fatal accident or injury, a natural disaster such as a flood, childhood sexual or physical assault/abuse, rape, childhood neglect, ethno-religious crisis, combat exposure, or torture. Any potential participant who did not meet all of the inclusionary criteria was excluded from the study.

The statistical power of 0.93 , which was considered enough for sample determination, was achieved using GPower 3.1 software (Faul, Erdfelder, Lang, \& Buchner, 2007; Faul, Erdfelder, Buchner, \& Lang, 2009). Thus, the sample size was computed as a function of the required significance level $(\alpha=.05)$, the desired power $(1-\beta=$ $0.93)$, and the estimated effect size in the population $\left(\mathrm{f}^{2}=0.21\right)$. The mean age of the REBT group was 23.07years, $\mathrm{SD}=3.57$, while that of the control group was 23.33 years, $\mathrm{SD}=4.82$. Of the 182 participants who took part in the study, those in the REBT group comprised $56(30.8 \%)$ male participants and $34(18.7 \%)$ female participants, while the waitlist control group comprised 59 (32.4\%) male participants and 33 (18.1\%) female participants. All participants were of Igbo ethnic origin.

\subsection{Measure}

\subsubsection{Trauma-Specific Beliefs Questionnaire (TBQ)}

This is a 25 -item questionnaire developed by the authors, specifically for this study based on previous studies on belief systems, trauma-specific events and experiences of traumatized individuals (Bride, Hatcher, \& Humble, 2009; Davidson \& Colket, 1997; Dawne, Shipherd, \& Resick, 2010; Horowitz, Wilner, \& Alvarez, 1979; Hyland et al., 2015; Hyland, Shevlin, Adamson, \& Boduszek, 2013; Kira, 2001; Kira et al., 2008; Tedeschi \& Calhoun, 1996; Vogt, Shipherd, \& Resick, 2010). To develop the TBQ, the researchers followed the guidelines for test construction and adaptation (Dawne, Shipherd, \& Resick, 2010; Jackson, 1971; Nunnally, 1978). The TBQ assesses participants' exposure to, and level of, irrationality and/or rationality regarding trauma-specific events or situations. The TBQ assesses the participants' beliefs and experiences that are trauma-based in the REBT approach. Sample items include, "It is awful to lose a loved one suddenly to death. I can't stand it," "I must stay away from other people because they are very dangerous," "It is a terrible thing to depend on humans when in trouble," and "It is worthless living in this threatening world". The TBQ uses a 5-point scale ranging from completely disagree (1) to completely agree (5). The minimum score is 25 and the maximum score is 125 . Higher scores indicate more extreme levels of trauma-specific irrational beliefs. The reliability of the TBQ using the data obtained from the current study participants is shown in Table 1 . The content and face validity of TBQ was checked by three experts in psychiatric science and two experts in educational research and statistics. These validators had doctoral degrees in their areas of specialization.

Table 1. Factor loadings, means, and standard deviations of each item

\begin{tabular}{llllllll}
\hline Items & Mean & SD & Skewness & Kurtosis & \multicolumn{2}{c}{ Factor Loading } & Cronbach's $\boldsymbol{\alpha}$ \\
\cline { 6 - 7 } & & & & $\mathbf{1}$ & $\mathbf{2}$ & $\mathbf{3}$ & .916 \\
Item 1 & 3.19 & 1.59 & -.241 & -1.43 & .934 & .918 \\
Item 2 & 2.94 & 1.38 & -.076 & -1.10 & .920 & .917 \\
Item 3 & 3.26 & 1.57 & -.337 & -1.37 & .918 & .917 \\
Item 4 & 2.84 & 1.40 & .037 & -1.19 & .917 & .916 \\
Item 5 & 2.78 & 1.39 & .239 & -1.22 & .917 & .918 \\
Item 6 & 3.20 & 1.59 & -.213 & -1.47 & .903 & .915 \\
Item 7 & 2.86 & 1.58 & -.013 & -1.59 & .895 & .917 \\
Item 8 & 3.16 & 1.54 & -.285 & -1.40 & .884 & .918 \\
Item 9 & 3.31 & 1.37 & -.309 & -.983 & .864 & .917 \\
Item 10 & 3.21 & 1.64 & -.220 & -1.61 & .817 & .919 \\
Item 11 & 3.59 & 1.19 & -.117 & -1.28 & & .971 & .919 \\
Item 12 & 3.77 & 1.02 & -.166 &. .745 & & .927 & .919 \\
Item 13 & 3.81 & .99 & -.304 & -.486 & & .898 & \\
\hline
\end{tabular}




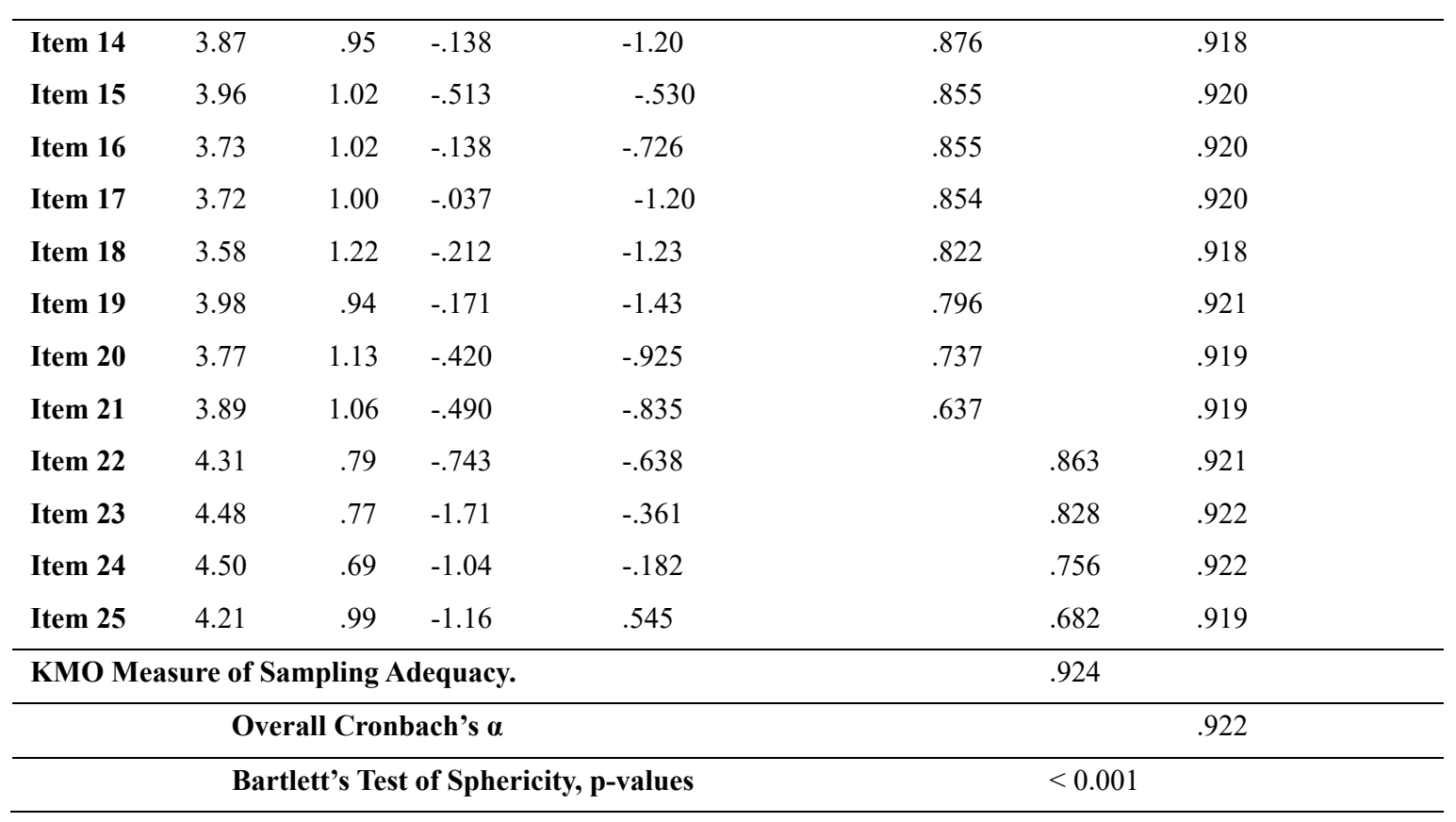

\subsection{Procedure}

Pretest, posttest, and follow-up assessments were administered to two study groups (experimental and waitlist control). At the onset, we displayed information about the research on bulletin boards in tertiary institutions within the study area. We further advertised the intervention in students' social and religious gatherings, as well as students' association meetings for up to three months. At baseline (pretest), a total of 278 undergraduate students who indicated that they had experienced or witnessed one or more traumatic events in focus group discussions were invited by the researchers, and their levels of trauma-specific irrational beliefs were measured using the TBQ. A total of 182 undergraduate students who first met the study criteria were selected for participation in the study. A computer-generated random list that was created by random allocation software was used for the allocation of participants (Saghaei, 2015). 90 participants were allocated to the experimental group and 92 participants were allocated to the waitlist control group by means of this simple randomization as in Ogbuanya et al. (2017a, 2017b).

Two of the researchers who are mental health counselors, group REBT practitioners, and counselor educators delivered the trauma-focused REBT intervention in group sessions which were attended in small groups of 8-10 participants. A trauma-focused REBT program manual developed by the researchers guided the intervention. All the participants in the experimental and waitlist control groups completed the TBQ posttest. We conducted follow-up assessment after four months for the treatment group participants. According to Eseadi, Obidoa, Ogbuabor, and Ikechukwu-Ilomuanya (2017), a waitlist control group is used as an untreated comparison group during an interventional study, but afterward, receives the treatment intervention. Thus, the waitlist control group participants in the current study were scheduled to start the trauma-focused REBT intervention immediately it ended for the treatment group.

\subsection{Intervention}

\subsubsection{Trauma-focused REBT Treatment Manual}

The trauma-focused REBT program manual was developed by the researchers specifically for this study to enable them to increase participants' awareness of their trauma-specific irrational beliefs and to aid the traumatized participants in overcoming these irrational beliefs. The trauma-focused program also aimed to build the participants' resilience and hardiness against traumatic events and posttraumatic cognitions. To develop the REBT manual, the authors followed existing guidelines for reporting behavioral interventions including the Standards for Quality Improvement Reporting Excellence (SQUIRE; Davidoff et al., 2008), Template for Intervention Description and Replication (TIDieR; Hoffmann et al., 2014), and the theory-based intervention development process by Heath, Cooke and Cameron (2015). Following the procedures described in these guidelines helped to ensure fidelity to the model and that the treatment that was delivered was the treatment intended.

During the development of the trauma-focused REBT program, the researchers adapted the techniques associated with earlier REBT-based manuals, trauma-focused group intervention modules and practice guidelines for group 
psychotherapy (American Group Psychotherapy Association Science to Service Task Force, 2007; Aronson \& Kahn, 2004; Beck, 2004; David, Kangas, Schnur, \& Montgomery, 2004; Eseadi, Anyanwu, Ogbuabor, \& Ikechukwu-Ilomuanya, 2015; Foy, Unger, \& Wattenberg, 2004; Layne, Murray, \& Saltzman, 2004; Rice, 2004; Sypniewski, 2016; Ulman, 2004) to aid participants in the modification of their trauma-specific beliefs and posttraumatic cognitions. Thus, the program involved the application of various therapeutic techniques, such as disputation, reframing, cognitive rehearsal, use of rational self-talk, use of traditional humorous songs, Socratic questioning and role-play. The intervention also consisted of direct teaching about the application of cognitive restructuring, relaxation, and desensitization techniques of REBT for the management of trauma-specific beliefs and emotions. The program consisted of ten home-based assignments given at the end of each therapeutic session. Overall, the trauma-focused program consisted of 20 therapeutic sessions of 80 minutes held over ten weeks, and a two-week follow-up was conducted after four months.

Cultural adaptations considered important in the delivery of this intervention were made. For example, at the start of therapy, the group leader uses a Nigerian proverb to reiterate the rule of confidentiality by saying "what is the heart of each member should not go beyond our neck," meaning members should learn and/or be able to keep all that each member shared in the group session secret.

According to Mulago in Magesa (1997), the life of a person can be grasped as it is shared. This worldview is also shared by majority of Nigerians. Also, a Nigerian language (Igbo) was used intermittently to better clarify certain points during therapy sessions. Furthermore, Nigerian traditional humorous songs considered culturally relevant to the intervention were used to help the participants. During each session, cultural factors influencing individual participants' interpretation of their traumatic experiences and posttraumatic cognitions were considered. According to Herbert and Forman (2010), an understanding of such cultural factors is important when treating clients' posttrauma and helping them in a culturally responsive manner.

The content of this manual was validated by three REBT practitioners with expertise in trauma-informed care and counseling and are familiar with Nigerian culture through expert-consensus validation procedure as used in previous studies (e.g. Eseadi, Anyanwu, Ogbuabor, \& Ikechukwu-Ilomuanya, 2015). The three REBT experts cross-checked the relevance and appropriateness of content of the program in terms of the group phases, activities, session goals and specific techniques. Their constructive comments were addressed by the researchers in terms of the agreement among them, and the revised version was returned to each of these experts for their final comments and review. Each of these REBT experts holds a doctoral degree in counseling studies.

\subsection{Design and Data Analysis}

This study used a randomized controlled trial design. We conducted Within x Between-subjects ANOVA with control vs. treatment as the between factor and time (pretreatment vs. posttreatment) as the within factor. This analysis gave results on three (3) sources of variance: main effect of treatment, main effect of time (pretreatment vs. posttreatment), and the time $\mathrm{x}$ group interaction effect. In this regard, the eta squared $\left(\eta^{2}\right)$ was reported as effect size measure. Given that we did not follow-up with the control group, we performed paired $t$-test analysis to determine whether the posttest and follow-up assessment scores differed between the students in the treatment group and/or whether the positive changes were sustained. Because of the t-test statistic, we calculated the Cohen's $d$, with magnitudes of effect sizes interpreted as follows: small $(d \geq 0.20)$, medium $(d \geq 0.50)$, and large $(d \geq 0.80)$ (Cohen, 1988). Before analysis, we screened for missing values and assumptions violation with the help of SPSS 20 (IBM Corp., 2011).

\section{Results}

Table 2. Participants' scores by treatment condition and time

\begin{tabular}{llllllll}
\hline Assessment & Group & $\boldsymbol{N}$ & $\boldsymbol{M}$ & $\boldsymbol{S D}$ & $\mathbf{9 5 \%}$ CI & Significance & Effect size \\
\hline Pretreatment & Treatment & 90 & 95.30 & 13.0 & $93.67-101.71$ & $.403^{*}$ & $.012^{\mathbf{\eta 2}^{2}}$ \\
& Waitlist control & 92 & 97.68 & 8.90 & & & \\
\multirow{3}{*}{ Posttreatment } & Treatment & 90 & 52.97 & 5.56 & $94.35-99.19$ & $<.001^{*}$ & $.814^{\mathbf{\eta}^{2}}$ \\
& Waitlist control & 92 & 98.71 & 9.29 & & & \\
Follow-up & Treatment & 90 & 51.48 & 6.91 & $48.95-54.02$ & $<.001^{* *}$ & $.502^{d}$ \\
\hline
\end{tabular}

$N=$ number of participants; $M=$ mean; $S D=$ standard deviation; $\mathrm{CI}=$ confidence interval; $\eta^{2}=$ eta squared; ${ }^{*}$ Significance value from ANOVA test; **Significance value from t-test; ${ }^{d}$ Cohen's $d$. 
Table 2 shows the results for the participants in the treatment group compared to the waitlist control group. With the TBQ, the results of the ANOVA test showed that there were no baseline differences in trauma-specific irrational beliefs between participants in the treatment and waitlist control conditions, $F(1,181)=.708, \mathrm{p}=.403$, $\eta^{2}=.012$. The ANOVA test conducted also revealed the main effect of treatment group, main effect of time (pretreatment vs. posttreatment), and the interaction effect. As measured by TBQ, we observed significant main effect of treatment group, $F(1,181)=141.15, p<.001, \eta^{2}=.702$. The results revealed that main effect of time (pretreatment vs. posttreatment) on trauma-specific beliefs was significant, $F(1,181)=261.909, p<.001, \eta^{2}$ $=.814$. (see Table 2). With the TBQ, our ANOVA results showed that time $\mathrm{x}$ group interaction effect for trauma-specific irrational beliefs was significant, $F(1,181)=238.99, p<.001, \eta^{2}=.799$. Figure 1 is a graphical presentation of this time $\mathrm{x}$ group interaction effect (see Figure 1). The paired sample $t$-test analysis of the intervention group's posttreatment scores, $t(89)=4.768, p<.001, d=.502$, was also significant, which is an indication of the REBT program's sustainability effect on trauma-specific irrational beliefs over time (see Table 2).

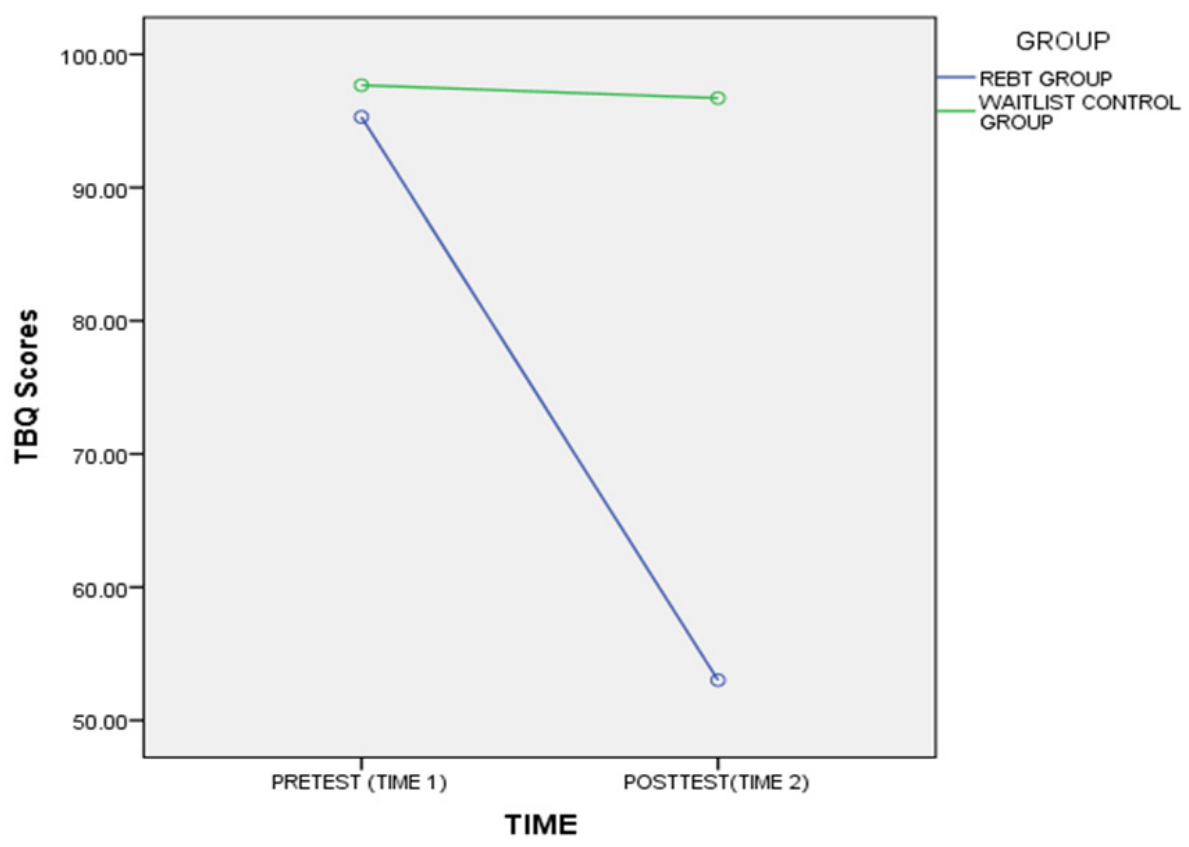

Figure 1. Time x Group interaction effect

\section{Discussion}

The aim of the present study was to investigate the effects that an REBT program had on trauma-specific irrational beliefs in a sample of undergraduate students in tertiary institutions in Southeast Nigeria. It was found that REBT brought about a significant decrease in the trauma-specific irrational beliefs of the students in the treatment group compared to those in the waitlist control group. Furthermore, the results showed that the positive gains were significantly sustained for the treatment group at four months follow-up. Our results support the assertion that clients who engage in an REBT program are able to dispute and overcome their irrational beliefs (Ellis, 1994; 1962; Walen, DiGiuseppe, \& Dryden, 1992). Our results also support a recent study in which the technique of the REBT model has been successful in mitigating the multiple effects of complex trauma including irrational thoughts and beliefs (Eseadi, Anyanwu, Ogbuabor, \& Ikechukwu-Ilomuanya, 2015).

Targeting and modifying trauma-specific irrational belief systems is an important area of trauma research that requires attention in the therapeutic treatment of traumatized individuals. Hyland et al. (2015) observed that general-level irrationality influences PTSD responses through a set of trauma-specific irrational beliefs. Thus, REBT practitioners need to focus on employing evidence-based strategies for identifying and challenging clients' trauma-specific dysfunctional beliefs and constructing more adaptive beliefs, emotions, and behavior. REBT practitioners must realize that a client's response to a traumatic life event with a set of irrational beliefs may play a critical role in predicting the progression of PTSD (Ellis, 2001), and thus provide an insight into what kind of 
REBT treatment process will be suitable for traumatized clients considering the different facets of the irrational beliefs of people suffering from PTSD. Given that the unhelpful consequences of trauma go beyond the healthcare system to educational sectors (Sypniewski, 2016), trauma-focused interventions based on the principles and practice of REBT are also very much warranted to assist those students and their families who have experienced one or more traumatic situations both in Nigeria and in other countries. Besides, in a recent study, Orosa et al. (2011) reported that traumatized individuals who had strong belief systems demonstrated better improvement in therapeutic process, and their preceding level of traumatization did not hamper the efficacy of the therapeutic assistance given to them.

Furthermore, trauma can negatively affect an individual's belief systems about the self, the world, and the future, but cultural context has a role to play in determining how well the individual is affected (SAMHSA, 2014). Therefore, in order to treat victims of trauma in future studies using the REBT approach, it is important to be familiar with their culture. More culturally responsive efforts should be directed at adaptation of culturally-appropriate contents and themes to facilitate the healing process of traumatized individuals in group therapy. For instance, their "social legacy" and their "social narrative" (Volkas, 2014) should be adapted into an REBT-based group intervention. The social legacy is the prescription parents pass on to their children about how to get along in the world. Some examples are: don't deviate from the norm, hate our enemy, take revenge, be happy, find what is self-fulfilling, love your enemy, and make the world a better place (Cooper et al., 2017). The social narrative is the story behind the prescription. For instance, a story of communal defeat or victory (Cooper et al., 2017). This is possible given that societies bond around a "chosen trauma" or "chosen glory" (Mojovic, 2011). Social legacies and social narratives should be clearly conveyed in the group therapy. Above all, community needs to be considered. That is, therapists have to be open to leaving their offices and adapting treatment in order to reconnect clients with their supportive community (Nicolas, Arntz, Hirsch, \& Schmiedigen, 2009).

\subsection{Limitations}

In spite of the positive outcomes, this study has some limitations. The study sample size consisted of only undergraduates in tertiary institutions in Southeast zone of Nigeria. Future research should include samples of undergraduates in various specialties. This will help researchers to determine whether the findings are generalizable to undergraduates in the different specialties. Furthermore, lack of data on the moderating effect of certain demographics of the study participants such as gender, marital status, age, religiosity, and place of residence, socioeconomic status also limits the contribution of this study. Future research should, therefore, investigate the moderating role of participants' demographics, such as their gender, marital status, age, religiosity, place of residence, and socioeconomic status on trauma-focused REBT program outcomes and posttraumatic cognitions.

Another limitation is that the effect of the REBT program was assessed using a measure (i.e., the TBQ) which is newly developed and has not been widely validated. We suggest that future research should make use of clinician-rated validated measures. There is also need to consider sociocultural factors and living conditions of trauma victims as they could impact on their recovery (see Orosa et al., 2011). Given the evidence on the role of irrational beliefs in posttraumatic stress responses (e.g. Hyland et al., 2015), REBT clinicians should take cognizance of context-specific variants of the irrational belief process while working with traumatized individuals. A more indirect, yet reliable estimate for the effectiveness of the treatment would be testing whether this program would have an effect on the levels of resilience and cognitive hardiness of individuals, which has been stated to be crucial for the treatment of trauma. The authors suggest that future studies should use a measure of depression or anxiety in order to test the effectiveness of the treatment.

In addition, not measure of PTSD symptoms and/or severity was used, so the benefits of REBT in the treatment of PTSD can only be inferred. The group leaders are also the evaluators of the study introducing a potential for bias. But evidence suggests that competent therapists produce better outcomes (Barber et al., 1996, 2006; Kuyken \& Tsivrikos, 2009). Another major limitation is that the scale's construct validity had never been tested. However, the results of the study point to some evidence of construct validation inasmuch as the scores improved as a result of intervention. Another major limitation of this study is that we had the waitlist control group do nothing. Thus, some experts may argue that the results of the study could be simply explained by the several weeks of intense contact with the treatment group and the participants figuring out what the researchers were looking for. The current study is also limited because even if the waitlist control was scheduled to receive the treatment at a later date, the results of such treatment are not presented.

Another limitation is the lack of any data on homework that is relevant to the outcome. Every member of the group completed the cognitive homework, however, there was no subjective evaluation of the treatment effectiveness. 
Nevertheless, the study can be viewed as a preliminary approach to introduce a model of psychological intervention in this area of high need. This very preliminary approach enabled the authors to provide this brief report regarding the effectiveness of an REBT group therapy on reduction of trauma-specific beliefs. Other limitations are group size and lack of information about attendance. Finally, we did not test whether there are any statistically significant differences between the treatment and control groups in terms of demographic differences or drop-out. Future researchers are encouraged to address the limitations of the current report.

\section{Conclusion}

This study of the impact of REBT treatment offers a useful initial investigation of how REBT can be used to alter trauma-specific beliefs. Specifically, the study examined the effectiveness of an REBT program on the reduction of undergraduate students' trauma-specific irrational beliefs. Based on the findings of the current study, the researchers concluded that the REBT program offered to the undergraduate students in Nigeria significantly decreased their trauma-specific irrational beliefs, relative to a waitlist control group. Overall, an REBT program can be helpful in altering trauma-specific irrational beliefs among undergraduate students in Nigeria. We hope that the report will add to the extant literature on emerging flexibility in group work, especially in developing countries such as Nigeria. Further clinical assessments with student populations are warranted.

\section{Acknowledgements}

The authors wish to acknowledge the effort of the study participants in making this research work successful. The authors are very thankful to the reviewers and the editor for their constructive comments which helped to improve the quality of this report.

\section{Competing Interests Statement}

The authors declare that there are no competing or potential conflicts of interest.

\section{References}

Addis, J., \& Bernard, M. E. (2002).Marital adjustment and irrational beliefs. Journal of Rational-Emotive \& Cognitive-Behavior Therapy, 20(1), 3-13.https://doi.org/10.1023/A:1015199803099

Ademuwagun, Z. A. (1969). The relevance of Yoruba medicine men in public health practice in Nigeria.Public Health Reports, 84(12), 1085-1091. https://doi.org/10.2307/4593761

American Group Psychotherapy Association (2004).Group interventions for treatment of psychological trauma. New York: Author.

American Group Psychotherapy Association Science to Service Task Force (2007).Practice guidelines for group psychotherapy. New York: American Group Psychotherapy Association.

American Psychiatric Association. (2013). Diagnostic and statistical manual of mental disorders (5th ed.). Washington, DC: Author. https://doi.org/10.1176/appi.books.9780890425596

American Psychological Association (2010).Ethical principles of psychologists and code of conduct. Washington, DC: Author.

American Psychological Association Presidential Task Force on Posttraumatic Stress Disorder in Children and Adolescents. (2008). Children and Trauma: Update for Mental Health Professionals. Washington, DC: American Psychological Association.

Anugwom, E., \& Anugwom, K. (2016). Socio-cultural factors in the access of women to HIV/AIDS prevention and treatment services in South-southern Nigeria. Iranian Journal of Public Health, 45(6), 754-760.

Anum, O. J., Zawua, T. P., \& Sar, T. T. (2016). A survey on the perceived socio-cultural risk factors influencing the spread of HIV/AIDS in the rural communities of Benue State, Nigeria. Sokoto Journal of Medical Laboratory Science, 1(1), 46-51.

Aronson, S., \& Kahn, G.B. (2004).Group interventions for treatment of psychological trauma (Module 3, group interventions for treatment of trauma in adolescents, pp. 89-144). New York: American Group Psychotherapy Association. https://doi.org/10.1037/e527872012-001

Beck, J. G., \& Coffey, S. F. (2005). Group cognitive behavioral treatment for PTSD: treatment of motor vehicle accident survivors. Cognitive and Behavioral Practice, 12(3), 267-277. https://doi.org/10.1016/S1077-7229(05)80049-5

Beck, R. (2004). Group interventions for treatment of psychological trauma (Module 8, unique aspects of group work with trauma, pp. 228-248). New York: American Group Psychotherapy Association. 
https://doi.org/10.1037/e527922012-001

Behenck, A. S., Gomes, J. B., \& Heldt, E. (2016).Patient rating of therapeutic factors and response to cognitive-behavioral group therapy in patients with obsessive-compulsive disorder.Issues in Mental Health Nursing, 37(6), 392-399. https://doi.org/10.3109/01612840.2016.1158335

Bisson, J., \& Andrew, M. (2007). Psychological treatment of post-traumatic stress disorder (PTSD).Cochrane Database of Systematic Review, (3), CD003388. https://doi.org/10.1002/14651858.CD003388.pub3

Bisson, J. I., Tavakoly, B., Witteveen, A. B., Ajdukovic, D., Jehel, L., Johansen, V. J., \& Olff, M. (2010). TENTS guidelines: Development of post-disaster psychosocial care guidelines through a Delphi process. British Journal of Psychiatry, 196(1), 69-74. https://doi.org/10.1192/bjp.bp.109.066266

Blayney, J. A., Read, J. P., \& Colder, C. (2016). Role of alcohol in college sexual victimization and postassault adaptation. Psychological Trauma: Theory, Research, Practice, and Policy, 8(4), 421-430. https://doi.org/10.1037/tra0000100

Bond, F. W., \& Dryden, W. (2000). How rational beliefs and irrational beliefs affect people's inferences: An experimental investigation. Behavioural and Cognitive Psychotherapy, 28(1), 33-43.

Brewin C. R., Andrews B., \& Valentine, J. D. (2000).Meta-analysis of risk factors for post-traumatic stress disorder in trauma-exposed adults. Journal of Consulting and Clinical Psychology, 68(5), 748-766. https://doi.org/10.1037/0022-006X.68.5.748

Bride, B. E., Hatcher, S. S., \& Humble, M. N. (2009). Trauma training, trauma practices, and secondary traumatic stress among substance abuse counselors. Traumatology, 15(2), 96-105. https://doi.org/10.1177/1534765609336362

Bryant-Davis, T., Ellis, M. U., \& Edwards, N. (2013). Therapeutic treatment approaches for ethnically diverse survivors of interpersonal trauma. In F. A. Paniagua, \& A. Yamada (Eds.), Handbook of multicultural mental health: assessment and treatment of diverse populations (2nd ed., pp. 505-524). New York: Academic Press. https://doi.org/10.1016/B978-0-12-394420-7.00026-6

Busari, A. O. (2014). Assessing prevalence of trauma and the risk of post-traumatic stress disorder among youths within the school community. African Journal for the Psychological Study of Social Issues, 17(1), $42-54$.

Cacciatore, J. (2007). Effects of support groups on post traumatic stress responses in women experiencing stillbirth. OMEGA-Journal of Death and Dying, 55(1), 71-90. https://doi.org/10.2190/M447-1X11-6566-8042

Choudhury, K. (2013). Managing Workplace Stress. India: Springer.https://doi.org/10.1007/978-81-322-0683-5

Cohen, J. (1988). Statistical power analysis for the behavioral sciences (2nd ed.). Hillsdale, NJ: Erlbaum.

Committee on the Assessment of Ongoing Effects in the Treatment of Posttraumatic Stress Disorder, \& Institute of Medicine. (2012). Treatment for posttraumatic stress disorder in military and veteran populations: initial assessment. Washington DC: National Academies Press.

Cooper, E. J., Hudson, J. S., Kranzberg, M. B., \& Motherwell, L. (2017).Current and future challenges in group therapy. International Journal of Group Psychotherapy, 67(sup1), S219-S239. https://doi.org/10.1080/00207284.2016.1238750

Corey, G. (1991). Theory and practice of counseling and psychotherapy (4th ed.). Pacific Grove, California: Brooks/Cole.

Cottraux , J., Note, I., Yao, S. N., de Mey-Guillard, C., Bonasse, F., Djamoussian, D., Mollard, E., Note, B., \& Chen , Y. (2008). Randomized controlled comparison of cognitive behavior therapy with Rogerian supportive therapy in chronic post-traumatic stress disorder: A 2-year follow-up. Psychotherapy and Psychosomatics, 77(2), 101-110. https://doi.org/10.1159/000112887

Counselling Directory (2017). Trauma. Retrieved July 15, 2017 from http://www.counselling-directory.org.uk/trauma.html

Courtois, C. A., \& Ford, J. D. (2016). Treatment of complex trauma: a sequenced, relationship-based approach. New York: Guilford Press.

Dada, A., Yinusa, W., \& Giwa, S. (2011). Review of the practice of traditional bone setting in Nigeria. African Health Sciences, 11(2), 262-265.

Dada-Adegbola, H. O. (2004). Socio-cultural factors affecting the spread of HIV/AIDS in Africa: a case study. 
African Journal of Medicine and Medical Sciences, 33(2), 179-182.

David, D. (2014). Rational Emotive Behavior Therapy. Oxford Bibliographies. https://doi.org/10.1093/obo/9780199828340-0147

David, D., \& DiGiuseppe, R. (2010). Social and cultural aspects of rational and irrational beliefs: a brief reconceptualization. In D. David, S. J. Lynn, \& A. Ellis (Eds.), Rational and irrational beliefs: research, theory, and clinical practice (pp. 49-61). New York: Oxford University Press. https://doi.org/10.1093/acprof:oso/9780195182231.003.0003

David, D., Kangas, M., Schnur, J. B., \& Montgomery, G. H. (2004). REBT depression manual: managing depression using rational emotive behavior therapy. Cluj-Napoca, Romania: Babes-Bolyai University.

David, D., Lynn, S. J., \& Ellis, A. (Eds.). (2010). Rational and irrational beliefs: research, theory, and clinical practice. New York: Oxford University Press.https://doi.org/10.1093/acprof:oso/9780195182231.001.0001

Davidoff, F., Batalden, P., Stevens, D., Ogrinc, G., \& Mooney, S. (2008). Publication guidelines for quality improvement in health care: Evolution of the SQUIRE project. Quality \& Safety in Health Care, 17, i3-i9. https://doi.org/10.1136/qshc.2008.029066

Davidson, J. R., \& Colket, J. T. (1997). The eight-item treatment outcome post-traumatic stress disorder scale: a brief measure to assess treatment outcome in post-traumatic stress disorder. International Clinical Psychopharmacology, 12(1), 41-45. https://doi.org/10.1097/00004850-199701000-00006

Diefenbeck, C. A., Klemm, P. R., \& Hayes, E. R. (2014).Emergence of Yalom's therapeutic factors in a peer-led, asynchronous, online support group for family caregivers. Issues in Mental Health Nursing, 35(1), 21-32. https://doi.org/10.3109/01612840.2013.836260

Dryden, W., David, D., \& Ellis, A. (2010). Rational emotive behavior therapy. In K. S. Dobson (Ed.), Handbook of cognitive-behavioral therapies (3rd ed., pp. 226-276). New York: Guilford Press.

DuHamel, K. N., Mosher, C. E., Winkel, G., Labay, L. E., Rini, C., Meschian, Y. M., ... Redd, W. H. (2010). Randomized clinical trial of telephone-administered cognitive-behavioral therapy to reduce post-traumatic stress disorder and distress symptoms after hematopoietic stem-cell transplantation. Journal of Clinical Oncology, 28(23), 3754-3761. https://doi.org/10.1200/JCO.2009.26.8722

Ellis A. (1962).Reason and emotion in psychotherapy. New York, NY: L. Stuart.

Ellis A. (1992). Group Rational-Emotive and Cognitive-Behavioral Therapy. International Journal of Group Psychotherapy, 42(1), 63-80.https://doi.org/10.1080/00207284.1992.11732580

Ellis, A. (1994). Reason and emotion in psychotherapy. New York, NY: BirchLane Press.

Ellis, A. (2001). Overcoming destructive beliefs, feelings, and behaviors: new directions for rational emotive behavior therapy. Amherst, NY: Prometheus Books.

Ellis, A., \& Dryden, W. (2007). The practice of rational emotive behavior therapy. New York: Springer. https://doi.org/10.1891/9780826122179

Erinosho, O. A. (2015). Cultural factors in mental illness among the Yoruba. International Journal of Group Psychotherapy, 27(4), 511-515.https://doi.org/10.1080/00207284.1977.11491332

Eseadi, C., Obidoa, M. A., Ogbuabor, S. E., \& Ikechukwu-Ilomuanya, A. B. (2017). Effects of group-focused cognitive-behavioral coaching program on depressive symptoms in a sample of inmates in a Nigerian prison. International Journal of Offender Therapy and Comparative Criminology. https://doi.org/10.1177/0306624X16687046

Eseadi, C., \& Ikechukwu-Ilomuanya, A. B. (2015). Cultural sensitivity in counselling: A panacea for cultural revival in Nigeria. Journal of Counselling and Communication, 1(5), 114-132

Eseadi, C., Ezurike, C. A., Obidoa, M. A., \& Ossai, V. O. (2017). Effect of rational emotive behavior therapy on reo-ffending thoughts of Nigerian prison inmates. The Educational Psychologist (NICEP), 11(1), 267-275.

Eseadi, C., Anyanwu, J. I., Ogbuabor, S. E., \& Ikechukwu-Ilomuanya, A. B. (2015). Effects of cognitive restructuring intervention program of rational-emotive behavior therapy on adverse childhood stress in Nigeria. Journal of Rational-Emotive \& Cognitive-Behavior Therapy, 34(1), 51-72. https://doi.org/10.1007/s10942-015-0229-4

Expert Consensus Panel for PTSD. (1999). The expert consensus guideline series. Treatment of Posttraumatic 
stress disorder. Journal of Clinical Psychiatry, 60(16), 3-76.

Faul, F., Erdfelder, E., Buchner, A., \& Lang, A.-G. (2009). Statistical power analyses using G*Power 3.1: Tests for correlation and regression analyses. Behavior Research Methods, 41(4), 1149-1160. https://doi.org/10.3758/BRM.41.4.1149

Faul, F., Erdfelder, E., Lang, A. G., \& Buchner, A. (2007). G*Power 3.A flexible statistical power analysis program for the social, behavioral, and biomedical sciences. Behavior Research Methods, 39(2), 175-191. https://doi.org/10.3758/BF03193146

Fenn, K., \& Byrne, M. (2013). The key principles of cognitive behavioural therapy. InnovAiT, 6(9), 579-585. https://doi.org/10.1177/1755738012471029

Foa, E. B., Ehlers, A., Clark, D. M., Tolin, D. F., \& Orsillo, S. M. (1999). The posttraumatic cognitions inventory (PTCI): Development and validation. Psychological Assessment, 11(3), 303-314. https://doi.org/10.1037/1040-3590.11.3.303

Forbes, D., Creamer, M., Phelps, A., Bryant, R., McFarlane, A., Devilly, G. J., ... \& Newton, S. (2007). Australian guidelines for the treatment of adults with acute stress disorder and post-traumatic stress disorder. Australian \& New Zealand Journal of Psychiatry, 41(8), 637-648. https://doi.org/10.1080/00048670701449161

Foy, D., Glynn, S., Schnurr, P., Jankowski, M., Wattenberg, M., Weiss, D., Marmar, C., \& Gusman F. (2000). Group therapy.In E. Foa, T. Keane, \& M. Friedman (Eds.), Effective treatments for PTSD (pp. 155-175). New York: Guilford Press.

Foy, D. W., Unger, W. S., \& Wattenberg, M. S. (2004). Group interventions for treatment of psychological trauma (Module 4, an overview of evidence- based group approaches to trauma with adults, pp.116-166). New York: American Group Psychotherapy Association. https://doi.org/10.1037/e527882012-001

Garakani, A., Hirschowitz, J., \& Katz, C. L. (2004).General disaster psychiatry. Psychiatric Clinics of North America, 27(3), 391-406. https://doi.org/10.1016/j.psc.2004.03.002

Gavit, O. A., David, D., DiGiuseppe, R., \& DelVecchio, T. (2011).The development and validation of the Parent Rational and Irrational Beliefs Scale. Procedia-Social and Behavioral Sciences, 30, 2305-2311. https://doi.org/10.1016/j.sbspro.2011.10.449

Giles, M. D., Nelson, A. L., Shizgal, F., Stern, E. M., Fourt, A., Woods, P., .. \& Classen, C. C. (2007). A multi-modal treatment program for childhood trauma recovery: Women Recovering from Abuse Program (WRAP). Journal of Trauma \& Dissociation, 8(4), 7-24.https://doi.org/10.1300/J229v08n04_02

Hamblen J. (2001). PTSD in children and adolescents, a National Center for PTSD fact sheet. Washington, DC: National Center for PTSD.

Harvey, M. R. (2007). Towards an ecological understanding of resilience in trauma survivors: Implications for theory, research, and practice. Journal of Aggression, Maltreatment \& Trauma, 14(1-2), 9-32.https://doi.org/10.1300/J146v14n01_02

Heath, G., Cooke, R., \& Cameron, E. (2015). A theory-based approach for developing interventions to change patient behaviours: a medication adherence example from paediatric secondary care. Healthcare, 3, 1228-1242. https://doi.org/10.3390/healthcare3041228

Heindel, C. (2011). Group therapy with adolescent girls in foster care: A treatment manual for clinicians at the Rutgers foster care counseling project (Doctoral dissertation, Rutgers University-Graduate School of Applied and Professional Psychology).

Herbert, J.D.,\& Forman, E.M. (2010).Cross-cultural perspectives on posttraumatic stress. In G.M. Rosen \& B.C. Frueh (Eds.), Clinician's Guide to Posttraumatic Stress Disorder (pp. 235-261). Hoboken, NJ: Wiley.https://doi.org/10.1002/9781118269961.ch10

Hien, D. A., Cohen, L. R., Miele, G.M., Litt, L. C., \& Capstick, C. (2004). Promising treatments for women with comorbid PTSD and substance use disorders. American Journal of Psychiatry, 161(8), 1426-1432. https://doi.org/10.1176/appi.ajp.161.8.1426

Hoffmann, T. C., Glasziou, P. P., Boutron, I., Milne, R., Perera, R., Moher, D., ... \& Michie, S. (2014). Better reporting of interventions: template for intervention description and replication (TIDieR) checklist and guide. $B M J, 348$, g1687. https://doi.org/10.1136/bmj.g1687

Horowitz, M. J. (2015). Effects of trauma on sense of self. Journal of Loss and Trauma, 20(2), 189-193. 
https://doi.org/10.1080/15325024.2014.897578

Horowitz, M. J., Wilner, N., \& Alvarez, W. (1979). Impact of Event Scale: a measure of subjective stress. Psychosomatic Medicine, 41(3), 209-218. https://doi.org/10.1097/00006842-197905000-00004

Hyland, P., Shevlin, M., Adamson, G., \& Boduszek, D. (2013).The role of trauma-specific irrational beliefs and sociodemographic risk factors in posttraumatic stress responses. Journal of Rational-Emotive \& Cognitive-Behavior Therapy, 31(3), 152-166. https://doi.org/10.1007/s10942-013-0167-y

Hyland, P., Shevlin, M., Adamson, G., \& Boduszek, D. (2015). Irrational beliefs in posttraumatic stress responses: a rational emotive behavior therapy approach. Journal of Loss and Trauma, 20(2), 171-188. https://doi.org/10.1080/15325024.2013.839772

IBM Corp. (2011). IBM SPSS Statistics for Windows, Version 20.0[Computer software]. Armonk NY: IBM Corp.

Jackson D. N. (1971). The dynamics of structured personality tests.Psychological Review, 78(3), 229-248.https://doi.org/10.1037/h0030852

Jegede, R. O. (1981). A study of the role of socio-cultural factors in the treatment of mental illness in Nigeria. Social Science \& Medicine. Part A: Medical Psychology \& Medical Sociology, 15(1), 49-54. https://doi.org/10.1016/0271-7123(81)90045-6

Kageyama, M., Nakamura, Y., Kobayashi, S., \& Yokoyama, K. (2016). Validity and reliability of the Japanese version of the Therapeutic Factors Inventory-19: A study of family peer education self-help groups. Japan Journal of Nursing Science, 13(1), 135-146. https://doi.org/10.1111/jjns.12098

Kar, N. (2011). Cognitive behavioral therapy for the treatment of post-traumatic stress disorder: a review. Neuropsychiatric Disease and Treatment, 7, 167-181.https://doi.org/10.2147/NDT.S10389

Kar, N., \& Misra, B. N. (2008). Mental Health Care Following Disasters. Bhubaneswar: Quality of Life Research and Development Foundation.

Karatzias, T., Ferguson, S., Gullone, A., \& Cosgrove, K. (2016). Group psychotherapy for female adult survivors of interpersonal psychological trauma: a preliminary study in Scotland. Journal of Mental Health, 25(6), 512-519. https://doi.org/10.3109/09638237.2016.1139062

Kaysen, D., Scher, C. D., Mastnak, J., \& Resick, P. (2005). Cognitive mediation of childhood maltreatment and adult depression in recent crime victims. Behavior Therapy, 36(3), 235-244. https://doi.org/10.1016/S0005-7894(05)80072-3

Kira, I. A. (2001). Taxonomy of trauma and trauma assessment. Traumatology, 7(2), 73-86. https://doi.org/10.1177/153476560100700202

Kira, I. A., Lewandowski, L., Templin, T., Ramaswamy, V., Ozkan B., \& Mohanesh, J. (2008). Measuring cumulative trauma dose, types, and profiles using a development-based taxonomy of traumas. Traumatology, 14(2), 62-87. https://doi.org/10.1177/1534765608319324

Klein, R., \& Schermer, V. (2000). Introduction and overview: Creating a healing matrix. In R. Klein, \& V. Schermer (Eds.), Group psychotherapy for psychological trauma (pp. 3-46). New York: Guilford Press.

Koopmans, P. C., Sanderman, R., Timmerman, I., \& Emmelkamp, P. M. G. (1994). The Irrational Beliefs Inventory (IBI): Development and psychometric evaluation. European Journal of Psychological Assessment, 10(1), 15-27. https://doi.org/10.1037/t15478-000

Kuriansky, J., \& Nemeth, D. G. (2013). A model for post-environmental disaster wellness workshops: preparing individuals and communities for hurricane anniversary reactions. Ecopsychology, 5(S1), S-38-S-45. https://doi.org/10.1089/eco.2013.0006

Lasebikan, V. O., Owoaje, E. T., \& Asuzu, M. C. (2012).Social network as a determinant of pathway to mental health service utilization among psychotic patients in a Nigerian hospital. Annals of African Medicine, 11(1), 12-20. https://doi.org/10.4103/1596-3519.91010

Layne, C. M., Murray, L., \& Saltzman, W. R. (2004).Group interventions for treatment of psychological trauma (Module 5, an overview of evidence-based group approaches to trauma with children and adolescents, pp. 169-178). New York: American Group Psychotherapy Association. https://doi.org/10.1037/e527892012-001

Liotta, L., Springer, C., Misurell, J. R., Block-Lerner, J., \& Brandwein, D. (2015). Group treatment for child sexual abuse: treatment referral and therapeutic outcomes. Journal of Child Sexual Abuse, 24(3), 217-237. https://doi.org/10.1080/10538712.2015.1006747 
Lynch, S. M. (2011). Restoring relationships: Group interventions for survivors of sexual traumas. In Bryant-Davis, T. (Ed.), Surviving sexual violence: A guide to recovery and empowerment (pp. 179-198). Plymouth, UK: Rowman \& Littlefield Publishers.

Magesa L. (1997). African religion: the moral traditions of abundant life. Maryknoll: Orbis Book.

Martin, R. C., \& Dahlen, E. R. (2004). Irrational beliefs and the experience and expression of anger.Journal of Rational-Emotive and Cognitive-Behavior Therapy, 22(1), 3-20. https://doi.org/10.1023/B:JORE.0000011574.44362.8f

McCann, I. L., Sakheim, D. K., \& Abrahamson, D. J. (1988). Trauma and victimization: a model of psychological adaptation. The Counseling Psychologist, 16(4), 531-594. https://doi.org/10.1177/0011000088164002

Mendelsohn, M., Herman, J. L., Schatzow, E., Kallivayalil, D., Levitan, J., \& Coco, M. (2011).The trauma recovery group: A guide for practitioners. New York: Guilford Press.

Mendelsohn, M., Zachary, R. S., \& Harney, P. A. (2007).Group therapy as an ecological bridge to new community for trauma survivors. Journal of Aggression, Maltreatment \& Trauma, 14(1-2), 227-243. https://doi.org/10.1300/J146v14n01_12

Mendes, D. D., Mello, M. F., Ventura, P., Passarela, C. M., \& Mari, J. J. (2008). A systematic review on the effectiveness of cognitive behavioral therapy for posttraumatic stress disorder. International Journal of Psychiatry in Medicine, 38(3), 241-259. https://doi.org/10.2190/PM.38.3.b

Messman-Moore, T. L., \& Resick, P. A. (2002).Brief treatment of complicated PTSD and peritraumatic responses in a client with repeated sexual victimization. Cognitive and Behavioral Practice, 9(2), 89-99. https://doi.org/10.1016/S1077-7229(02)80003-7

Mojovic, M. (2011).Manifestations of psychic retreats in social systems. In E. Hopper \& H. Weinberg (Eds.), The social unconscious in persons, groups, and societies (pp. 209-232). London, UK: Karnac. https://doi.org/10.4324/9780429483233-12

Mueser, K. T., Rosenberg, S. D., Xie, H., Jankowski, M. K., Bolton, E. E., Lu, W., ... \& Wolfe, R. (2008). A randomized controlled trial of cognitive-behavioral treatment for posttraumatic stress disorder in severe mental illness. Journal of Consulting and Clinical Psychology, 76(2), 259-271. https://doi.org/10.1037/0022-006X.76.2.259

National Institute for Clinical Excellence (2005). Post-traumatic stress disorder (PTSD): The management of PTSD in adults and children in primary and secondary care. NICE Clinical Guideline No. 26. London: National Institute for Clinical Excellence.

Nicolas, G., Arntz, D., Hirsch, B., \& Schmiedigen, A. (2009).Cultural adaptation of a group treatment for Haitian American adolescents. Professional Psychology: Research and Practice, 40, 378-384. https://doi.org/10.1037/a0016307

Northwest Frontier Addiction Technology Transfer Center (NFATTC). (2004). Group skills - Part 1: approaches to group therapy. Addiction Messenger, 7(4). Retrieved from www.nfattc.org.

Nunnally J. (1978). Psychometric theory. New York: McGraw-Hil.

Nwoga, C. N., Audu, M. D., \& Obembe, A. (2016).Prevalence and correlates of posttraumatic stress disorder among medical students in the University of Jos, Nigeria. Nigerian Journal of Clinical Practice, 19(5), 595-599. https://doi.org/10.4103/1119-3077.188704

Ogbuanya, T. C., Eseadi, C., Orji, C. T., Ede, M. O., Ohanu, I. B., \& Bakare, J. (2017a). Effects of rational emotive occupational health therapy intervention on the perceptions of organizational climate and occupational risk management practices among electronics technology employees in Nigeria. Medicine, 96(18), e6765. https://doi.org/10.1097/MD.0000000000006765

Ogbuanya, T. C., Eseadi, C., Orji, C. T., Ohanu, I. B., Bakare, J., \& Ede, M. O. (2017b). Effects of rational emotive behavior coaching on occupational stress and work ability among electronics workshop instructors in Nigeria.Medicine, 96(19), e6891. https://doi.org/10.1097/MD.0000000000006891

Oluwabamide, A. J., \& Umoh, J. O. (2011). An assessment of the relevance of religion to health care delivery in Nigeria: case of Akwalbom State. Journal of Sociology and Social Anthropology, 2(1), 47-52. https://doi.org/10.1080/09766634.2011.11885547

Omololu, B., Ogunlade, S. O., \& Alonge, T. O. (2002). The complications seen from the treatment by traditional 
bone setters. West African Journal of Medicine, 21(4), 335-337. https://doi.org/10.4314/wajm.v21i4.28014

Onana, V. (2016). Post-traumatic stress disorder: why it may be on the increase. Nigerian Tribune September 15. Retrieved from http://tribuneonlineng.com/post-traumatic-stress-disorder-may-increase/

Onyechi, K. C. N., Eseadi, C., Okere, A. U., \& Otu, M. S. (2016). Effects of rational-emotive health education program on HIV risk perceptions among in-school adolescents in Nigeria. Medicine, 95(29), e3967. https://doi.org/10.1097/MD.0000000000003967

Onyencho, V. C., Omeiza, B., \& Wakil, M. A. (2014). Post-traumatic stress disorder and psychological well-being among university of Maiduguri students. Ife Psychologia, 22(1), 195-201.

Orosa, F. J. E, Brune, M., Huter, K., Fischer-Ortman, J., \& Haasen, C. (2011). Belief systems as coping factors in traumatized refugees: a prospective study. Traumatology, 17(1), 1-7. https://doi.org/10.1177/1534765609358468

Osujih, M. (1993). Exploration of the frontiers of tradomedical practices: basis for development of alternative medical healthcare services in developing countries. Journal of the Royal Society of Health, 113(4), 190-194. https://doi.org/10.1177/146642409311300409

Owens, G. P., Pike, J. L., \& Chard, K. M. (2001). Treatment effects of cognitive processing therapy on cognitive distortions of female child sexual abuse survivors. Behavior Therapy, 32(3), 413-424. https://doi.org/10.1016/S0005-7894(01)80028-9

Owens, G. P., \& Chard, K. M. (2001).Cognitive distortions among women reporting childhood sexual abuse. Journal of Interpersonal Violence, 16(2), 178-191. https://doi.org/10.1177/088626001016002006

Oyebola, D. D. O. (1980). Yoruba traditional bonesetters: the practice of orthopaedics in a primitive setting in Nigeria. Journal of Trauma and Acute Care Surgery, 20(4), 312-322. https://doi.org/10.1097/00005373-198004000-00006

Ozer, E. J., Best S. R., Lipsey T. L., \& Weiss D. S. (2003). Predictors of posttraumatic stress disorder and symptoms in adults: A meta-analysis. Psychological Bulletin, 129(1), 52-73. https://doi.org/10.1037/0033-2909.129.1.52

Pearlman, L. A., \& Saakvitne, K. W. (1995). Treating therapists with vicarious traumatization and secondary traumatic stress disorders. In C.R. Figley (Ed.), Compassion fatigue: Coping with secondary traumatic stress disorder in those who treat the traumatized (pp. 150-177). London: Brunner-Routledge.

Quiros, L., \& Berger, R. (2015). Responding to the sociopolitical complexity of trauma: An integration of theory and practice. Journal of Loss and Trauma, 20(2), 149-159. https://doi.org/10.1080/15325024.2013.836353

Rice, A. (2015). Common therapeutic factors in bereavement groups. Death Studies, 39(3), 165-172. https://doi.org/10.1080/07481187.2014.946627

Rice, C. A. (2004). Group interventions for treatment of psychological trauma (Module 6, the later stage: the role of group interventions in coping with the aftermath of traumatic events, pp. 180-192). New York: American Group Psychotherapy Association.https://doi.org/10.1037/e527902012-001

Saghaei, M. (2004). Random allocation software [Computer software]. Retrieved from $\mathrm{http}: / /$ mahmoodsaghaei.tripod.com/Softwares/randalloc.html.

Santos, L. F., Oliveira, L. M. D. A. C., Munari, D. B., Peixoto, M. K. A. V., \& Barbosa, M. A. (2012). Therapeutic factors in group support from the perspective of the coordinators and group members. ActaPaulista de Enfermagem, 25(1), 122-127. https://doi.org/10.1590/S0103-21002012000100021

Schermer, V. L. (2004). Group interventions for treatment of psychological trauma (Module 9, identification and management of masked trauma reactions in groups, pp. 250-284). New York: American Group Psychotherapy Association.https://doi.org/10.1037/e527932012-001

Shemesh, E., Annunziato, R. A., Weatherley, B. D., Cotter, G., Feaganes, J. R., Santra, M., Yehuda, R., \& Rubinstein, D. (2011). A randomized controlled trial of the safety and promise of cognitive-behavioral therapy using imaginal exposure in patients with posttraumatic stress disorder resulting from cardiovascular illness.Journal of Clinical Psychiatry, 72(2), 168-174.https://doi.org/10.4088/JCP.09m05116blu

Sijbrandij, M., Olff, M., Reitsma, J. B., Carlier, I. V., de Vries, M. H., \& Gersons, B. P. (2007). Treatment of acute posttraumatic stress disorder with brief cognitive behavioral therapy: A randomized controlled trial. American Journal of Psychiatry, 164(1), 82-90. https://doi.org/10.1176/ajp.2007.164.1.82 
Substance Abuse and Mental Health Administration. (2012). Substance abuse treatment: group therapy in-service training. HHS Publication No. (SMA) SMA-11-4664. Rockville, MD: Substance Abuse and Mental Health Services Administration.

Substance Abuse and Mental Health Services Administration. (2014). Trauma-informed care in behavioral health services. Treatment Improvement Protocol (TIP) Series 57.HHS Publication No. (SMA) 13-4801. Rockville, MD: Substance Abuse and Mental Health Services Administration.

Sypniewski, R. L. (2016). Increasing the awareness of trauma informed care in the school setting: Giving practitioners the tools to actively participate in trauma related care (Doctoral dissertation, University of San Francisco).

Tagurum, Y. O., Chirdan, O. O., Obindo, T., Bello, D. A., Afolaranmi, O. T., Hassan Z. I., \& Yilgwan, C. (2014). Prevalence of violence and symptoms of post-traumatic stress disorder among victims of ethno-religious conflict in Jos, Nigeria. Journal of Psychiatry, 18(1), 178. https://doi.org/10.4172/Psychiatry.1000178

Tedeschi, R. G., \& Calhoun, L. G. (1996). The posttraumatic growth inventory: measuring the positive legacy of trauma. Journal of Traumatic Stress, 9(3), 455-471.https://doi.org/10.1002/jts.2490090305

Tran, K., Moulton, K., Santesso, N., \& Rabb, D. (2016). Cognitive processing therapy for post-traumatic stress disorder: a systematic review and meta-analysis (CADTH Health Technology Assessment No. 141). Ottawa, Canada: Canadian Agency for Drugs and Technologies in Health.

Tummala-Narra, P., Kallivayalil, D., Singer, R., \& Andreini, R. (2012). Relational experiences of complex trauma survivors in treatment: Preliminary findings from a naturalistic study. Psychological Trauma: Theory, Research, Practice, and Policy, 4(6), 640-648. https://doi.org/10.1037/a0024929

Turner, M. J. (2016). Rational Emotive Behavior Therapy (REBT), Irrational and Rational Beliefs, and the Mental Health of Athletes. Frontiers in Psychology, 7, 1423. https://doi.org/10.3389/fpsyg.2016.01423

Udosen, A. M., Otei, O. O., \& Onuba, O. (2006). Role of traditional bone setters in Africa: experience in Calabar, Nigeria. Annals of African Medicine, 5(4), 170-173.

Ulman, .H. (2004). Group interventions for treatment of psychological trauma (Module 1, group interventions for treatment of trauma in adults, pp. 13-59). New York: American Group Psychotherapy Association. https://doi.org/10.1037/e527852012-001

van der Kolk, B. (1997). Post-traumatic stress disorder and memory.Psychiatric Times (online serial), 14(3).

Van Emmerik, A. A., Kamphuis, J. H., \& Emmelkamp, P. M. (2008).Treating acute stress disorder and posttraumatic stress disorder with cognitive behavioral therapy or structured writing therapy: A randomized controlled trial.Psychotherapy and Psychosomatics, 77(2), 93-100.https://doi.org/10.1159/000112886

Vogt, D. S., Shipherd, J. C., Resick, P. A. (2010). Posttraumatic Maladaptive Beliefs Scale: Evolution of the Personal Beliefs and Reactions Scale. Assessment, 19(3), 308-317. https://doi.org/10.1177/1073191110376161

Volkas, A. (2014). Drama therapy in the repair of collective trauma. In N. Sajnani \& D. R. Johnson (Eds.), Trauma-informed drama therapy: transforming clinics, classrooms, and communities (pp. 41-68). Springfield, IL: Charles C. Thomas.

Wagner, A. W. (2003). Cognitive-behavioral therapy for posttraumatic stress disorder: applications to injured trauma survivors. Seminars in Clinical Neuropsychiatry, 8(3), 175-187. https://doi.org/10.1016/S1084-3612(03)00018-2

Walen, S. R., DiGiuseppe, R., \& Dryden, W. (1992). A practitioner's guide to rational-emotive therapy (2nd ed.). New York, NY: Oxford University Press.

Wenninger, K., \& Ehlers, A. (1998).Dysfunctional cognitions and adult psychological functioning in child sexual abuse survivors. Journal of Traumatic Stress, 11(2), 281-300. https://doi.org/10.1023/A:1024451103931

Wöller, W. (2010). GruppenpsychotherapiebeitraumatisiertenPatientinnen: Konzepte und Stand der Forschung [Group psychotherapy for traumatized patients: Concepts and state of research]. Gruppenpsychotherapie und Gruppendynamik, 46(1), 4-21. https://doi.org/10.13109/grup.2010.46.1.4

Wood, A. G., Turner, M. J., Barker, J. B., \& Higgins, S. J. (2017). Investigating the effects of irrational and rational self-statements on motor-skill and hazard-perception performance. Sport, Exercise, and Performance Psychology, 6(4), 384-400. https://doi.org/10.1037/spy0000095 
Yalom, I. D., \& Leszcz, M. (2005). Theory and practice of group psychotherapy. New York, NY: Basic Books.

Zoellner, T., Rabe, S., Karl, A., \& Maercker, A. (2011). Post-traumatic growth as outcome of a cognitive-behavioural therapy trial for motor vehicle accident survivors with PTSD. Psychotherapy and Psychosomatics, 84(2), 201-213. https://doi.org/10.1348/147608310X520157

\section{Copyrights}

Copyright for this article is retained by the author(s), with first publication rights granted to the journal.

This is an open-access article distributed under the terms and conditions of the Creative Commons Attribution license (http://creativecommons.org/licenses/by/4.0/). 